cibido mil y cuatrocientos reales a cuenta de los tres mil y trescientos en que fueron concertados con el dicho convento que me han de dar como fuere haciendo la obra que han de irme dando dinero de forma que al fin del dicho tiempo me han de acabar de pagar la dicha cantidad y de la dicha cantidad otorgo carta de pago y me doy por entregado de ellos y de los dichos mil y cuatrocientos reales con lo que renuncio la ejecución de la inumerata, pecunia y leyes de la entrega, prueba del recibo como en ella se contiene y si así no hiciere y cumpliere lo contenido en la dicha escritura pueda buscar el dicho convento otro maestro del dicho oficio que le acabe y por lo que más le costare y recibido no ha de poder enviar y ejecutar a la dicha ciudad de Sevilla ni a otra parte donde estuviere y mis bienes y a la persona que a él le refiere me obligo de le dar y pagar quinientos reales de salario en cada un día de todos los que se ocupará en la ida, estancia y vuelta las veces que fuere necesaria hasta la real paga todo lo que él pagare como lo principal con sólo declaración y juramento de la parte del dicho convento o de quien su causa hubiere en que ha de quedar y queda diferido sin otra prueba de que en ello y para ellos y al cumplimiento obligo mi persona y bienes habidos y por haber y doy poder cumplido bastante a las justicias y jueces de Su Majestad para la ejecución de ello y en él por oficiales de la ciudad de Carmona cuyo fuero y jurisdicción me someto con mi persona y bienes...

Hecha la carta en Carmona en fecha un día del mes de diciembre del seiscientos y cincuenta y dos años y el dicho otorgante lo firmó, y presentó por testigos de su conocimiento a Diego Muñoz y Agustín Franco, vecinos de Sevilla, estantes en esta ciudad, los cuales debajo de juramento que hicieron en forma de derecho dijeron que conocen al dicho Juan de Valdés y que es el contenido que otorgó la escritura pública siendo testigos el licenciado Juan Moreno y el licenciado Francisco Romero y Francisco Nolda, vecinos de Carmona.

(A.P.C. Escribano Francisco Muñoz de Alanís, 1652, ff. 620-620v)

Fernando de la Villa Nogales

Esteban Mira Caballos

\title{
SANTO DOMINGO DE LA CALZADA - SILOS - COMPOSTELA LAS REPRESENTACIONES DEL «ÁRBOL DE JESÉ» EN EL TARDORROMÁNICO HISPANO: PARTICULARIDADES ICONOGRÁFICAS *
}

Hace ya algunos años, y al retirar para su restauración el magnífico retablo de Damián Forment que presidía el altar mayor de la catedral de Santo Domingo de la Calzada, aparecieron decorando los frentes de los cuatro soportes centrales de la girola una serie de placas relivarias de fines del siglo xII que, siguiendo el trazado de las aristas del polígono del presbiterio, se elevan desde la base de las pilastras hasta traspasar la línea de imposta que marca la transición entre el cuerpo de ventanas y la zona de la tribuna. La decoración de estas placas alterna los motivos vegetales en las pilastras primera y tercera con la talla de figuras monumentales en la segunda y cuarta ${ }^{1}$. El descubrimiento es de vital importancia no sólo por la elevada calidad técnica de las esculturas, sino por las particularidades iconográficas que presenta el tema allí representado ${ }^{2}$.

* El presente artículo es parte de un estudio mucho más amplio dirigido por el Prof. D. Isidro G. Bango Torviso, concebido como trabajo de investigación y presentado en el Departamento de Historia y Teoría del Arte de la Universidad Autónoma de Madrid. Elaborado durante el otoño-invierno de 1997, con posterioridad a su depósito en la redacción de Archivo Español de Arte han visto la luz las actas del Simposio celebrado en enero de 1998 sobre la catedral tardorrománica de La Calzada, dentro de las cuales destacamos la intervención del Prof. Yarza, quien dedica un amplio apartado al estudio iconográfico de las mismas piezas que aquí tratamos, y con cuyas conclusiones nos complace coincidir en su mayor parte.

1 Para la numeración de las pilastras se ha comenzado por la más próxima al lado del Evangelio, la de la izquierda según el espectador

2 De la aparición de estos importantes restos se hizo eco Minerva Sáenz, aunque ni los citó en su conjunto, ni los analizó de modo pormenorizado, refiriéndose únicamente a dos de las figuras integrantes, el Rey David y la Trinidad: Sáenz Rodríguez, M., «Temas iconográficos y ornamentales de la escultura monumental románica en La Rioja», en Berceo, n. ${ }^{\circ}$ 128 (1995), pp. 47-90. Un completo estudio en materia de iconografía, cronología, estilo y talleres es el que acabamos de aludir del Prof. Yarza, a cuya lectura remitimos para un conocimiento en profundidad de todos estos aspectos: Yarza Luaces, J., «La escultura monumental de la Catedral Calceatense», La cabecera de la Catedral calceatense y el Tardorrománico hispano. Actas del Simposio en Santo Domingo de la Calzada, 29 al 31 de enero de 1998. Santo Domingo de la Calzada, 2000, pp. 151-205. 
La presencia entre toda la serie de personajes como Jesé, David, Isaías, la Virgen y una Majestad, dispuestos jerárquicamente en sentido ascendente e intercalados por elementos vegetales a modo de tallos nos conduce a pensar que nos encontramos ante una representación del Árbol de Jesé, motivo que figura plásticamente la genealogía de Cristo ${ }^{3}$ según nos la narra San Mateo al comienzo de su evangelio ${ }^{4}$, y que toma la metáfora vegetal de una profecía de Isaías quien, tras predecir al pueblo de Israel que sería liberado de la furia de los asirios, les anuncia el nacimiento del Mesías, su justicia, sabiduría y santidad. Como observa el Abbé Corblet, él considera el reino de Judá como un tronco prácticamente muerto pero cuya savia hará revivir un brote que salvará a Israel ${ }^{5}$ : «Saldrá un vástago del tronco de Jesé, y un retoño de sus raíces brotará» ${ }^{6}$. La hipótesis, de confirmarse, revestiría la importancia de añadir un ejemplo más a las dos únicas representaciones de esta temática conocidas hasta el momento dentro del panorama románico peninsular: las esculpidas en el parteluz del Pórtico de la Gloria de la catedral de Santiago y en uno de los relieves del machón suroccidental del claustro de Santo Domingo de Silos.

\section{$E l$ «Árbol de Jesé» en la literatura y en el arte de los siglos III-XII. Breve reseña}

Debemos a Tertuliano, a comienzos del siglo iII, la primera interpretación conocida de la profecía en la que se identifica a Jesé, padre de David, con la raíz de la que surge el tallo, que es María, y a la flor - (o fruto ) - que de él brota, con Cristo su hijo ${ }^{7}$. Sin apenas variaciones es ésta la idea que nos transmiten los patriarcas y teólogos altomedievales que tratan posteriormente el tema como San Ambrosio, San Jerónimo, San León Magno o Rábano Mauro ${ }^{8}$. Como apuntan todos aquellos que han estudiado el origen de este motivo iconográfico, no debe extrañar la asociación de la Virgen con el tallo dada la similitud que en latín tienen ambos términos - virgo y virga-, lo que se prestaba fácilmente al juego de palabras como queda claramente de manifiesto en alguno de estos escritos ${ }^{9}$. Ya en el siglo XII, Bernardo de Claraval

${ }^{3}$ No son numerosos los trabajos dedicados de forma monográfica al estudio de este tipo iconográfico. El primero de ellos fue el que realizó a mediados del pasado siglo el Abbé Corblet, J., «Étude iconographique sur l'Arbre de Jessé», Revue de l'Art chrétien, t. IV (1860), pp. 49-61; 114-125 y 170-181. El siguiente en concederle un capítulo importante dentro de su obra es Mâle, É.: L'Art religieux du xue siècle en France. Paris, 1922, pp. 168 y ss. La monografía más amplia y que, pese a su antigüedad sigue siendo el punto de referencia obligado al tratar el tema es el libro de Watson, A., The Early Iconography of the Tree of Jesse. London-Oxford, 1934. Por otra parte, hubo ciertos intentos como los de Kingsley Porter y Coomaraswamy por intentar vincular este iconograma a composiciones chinas o indias. Su postura queda recogida por Guerrero Lovillo, J., «Sobre el origen indio del árbol de Jessé», Archivo Español de Arte, XVII (1944), pp. $330-333$.

Aparte de estas obras de carácter general, los principales ejemplos conservados han sido objeto de estudios específicos siendo fundamentales para el conocimiento de los españoles los dos artículos de la norteamericana Valdez del Álamo, E. "Visiones y profecía: el Árbol de Jesé en el claustro de Silos», El Románico en Silos. IX Centenario de la Consagración de la Iglesia y Claustro. Abadía de Silos, 1990, pp. 173-202; e Id., «Relaciones artísticas entre Silos y Santiago de Compostela», Actas del Simposio Internacional sobre «O Pórtico da Gloria e a Arte do seu Tempo». Santiago de Compostela, 1991, pp. 199-221.

${ }^{4}$ «Libro de la generación de Jesucristo, hijo de David, hijo de Abraham: (...)». Mt. 1, 1-17, en la que comenzando por Abraham, recoge la serie de los reyes de Judá encabezada por David, de cuya estirpe proviene José, esposo de María, la madre de Jesús.

${ }^{5}$ Corblet, J., art. cit., p. 50

6 «t egredietur virga de radice Iesse, et flos de radice eius ascendet». Is. $11,1$.

7 «Virga ex radice, Maria ex David: flos ex virga, Filius Mariae, qui dicitur Jesus Christus; ipse erit et fructus». Tertuliano, De Carne Christi, 21, 5. (Cf. en Corblet, J., art. cit., p. 50).

${ }^{8}$ Una buena síntesis de textos escogidos de estos y otros autores en los que se identifica a la Virgen con la rama que brota de Jesé y a Jesús con el fruto queda recogida en el primer capítulo de la citada obra de Watson, titulado precisamente «The Virga in Literature», pp. 1-8.

9 San Jerónimo: «Nos autem virga de radice Iesse, sanctam Mariam Virginem intelligamus», (P. L., XXIV, 144), o, San León Magno: «... In qua virga non dubie beata Virgo Maria praedicta est», (P. L., LIV, 204).- Ibídem. 
vinculará el texto de Isaías al episodio de la Anunciación como el momento preciso en el que se materializa la promesa hecha por Yahvé a su pueblo por boca del profeta ${ }^{10}$.

La representación plástica de la genealogía de Cristo según estas fuentes parece que cuenta con sus manifestaciones más antiguas desde el siglo XI ${ }^{11}$, pero habrá que esperar hasta mediados de la siguiente centuria para que el tema alcance una codificación definitiva, para que se le dote de unas características que, con ligeras variantes, serán las seguidas por la mayoría de los artistas a partir de este momento. Esta «vraie formule» tal como la definió Mâle ${ }^{12}$, queda fijada en una de las vidrieras del coro de la Abadía de Saint-Denis, realizada en 1144 por orden de Suger ${ }^{13}$, y requiere la figuración de una serie de personajes fijos: a) la figura recostada de Jesé; b) la inclusión en la secuencia genealógica de los Reyes de Judá; c) la Virgen, Cristo y las siete palomas símbolo de los Siete Dones del Espíritu Santo; d) profetas ${ }^{14}$. El esquema fue inmediatamente copiado en otra vidriera de la fachada occidental de la Catedral de Chartres tan sólo seis años después, ca. 1150.

\section{Estudio iconográfico de los restos aparecidos. Particularidades hispanas}

Según esto, las diferencias iconográficas entre el prototipo francés y el ejemplo riojano son más numerosas que las coincidencias, y sin embargo, este último mantiene claras analogías con los hasta ahora únicos representantes del tema conservados de nuestro románico peninsular, y que han sido aceptados unánimemente por los investigadores como tales. Dos son las características fundamentales que diferencian los tres conjuntos hispanos del resto de los ejemplos europeos, ya sean anteriores o posteriores. Tanto en Santo Domingo de la Calzada, como en Silos y Compostela, el motivo genealógico queda rematado por una representación de la Trinidad «Paternitas» en la que es Dios Padre quien sostiene sobre sus rodillas al Niño Dios y no la Virgen, que lejos de ser la Theotokos de los ejemplos ultrapirenaicos, aparece vinculada al episodio de la Anunciación. Sirviéndonos como referencia del esquema-tipo apuntado algo más arriba, vamos a tratar de analizar iconográficamente cada uno de los personajes para así poder sacar unas conclusiones válidas.

- La cuarta pilastra se inicia con la figura tal vez más innovadora en lo que a postura se refiere de todo el conjunto. Si bien los errores de composición, proporciones y articulación de los miembros son manifiestos, es de destacar que se ha huido completamente de la frontalidad dominante en el resto de las piezas para colocar este personaje de perfil, con una pierna ligeramente avanzada sobre la que carga el peso del cuerpo mientras que la otra queda algo más retrasada y flexionada en posición de reposo a la vez que apoya una de sus manos sobre la cadera correspondiente. La cabeza no mira hacia el espectador sino que vuelta hacia arriba, dirige sus ojos hacia lo que se desarrolla en la parte superior, sensación ascendente que se ve reforzada por la posición del otro brazo, levantado y con la mano abierta en actitud de dirigir la atención hacia algún punto por encima de ella. De la parte posterior de su cabeza surge lo que

\footnotetext{
${ }^{10}$ San Bernardo, «In Laudibus Virginis Matris», en Obras Completas. (Ed. bilingüe preparada por los monjes cistercienses de España). Madrid, 1983-1988. Vol. II, pp. 597 y ss.

"Watson, A., op. cit., pp. 83-141.

12 Mâle, É., op. cit., p. 74.

13 «Vitrearum etiam novarum praeclaram varietatem, ab ea prima quae incipit a Stirps Jesse in capite ecclesiae usque ad eam quae superest principali portae in introitu ecclesiae, tam superius quam inferius magistrorum multorum de diversis nationibus manu exquisita depingi fecimus.». Suger, Liber de Rebus in Administratione Sua Gestis, cap. XXXIV. (Ed. por Panofsky, E., Abbot Suger on the Abbey Church of St.-Denis and its Art Treasures. Princeton, 1979, pp. 72-74).

14 Watson, A., op. cit., p. 78.
} 
parece ser un tallo, atributo único que nos permite identificarlo con Jesé, bíblico personaje padre del Rey David. (Fig. 1).

La norma común determina que Jesé, representado con barba y como un anciano, aparezca recostado en actitud somnolienta y con la cabeza apoyada sobre una mano ${ }^{15}$, mientras que de su cintura arranca la rama sobre la que se dispondrán el resto de los protagonistas. Si en Silos y Compostela esto se observa rigurosamente, en Santo Domingo de la Calzada se nos muestra como un personaje relativamente joven, imberbe, que permanece de pie mientras que el elemento vegetal brota de detrás de su cabeza en vez de hacerlo desde su costado. Aunque la imagen no es frecuente, sí cuenta, no obstante, con precedentes iconográficos claros entre los que cabe destacar una de las esculturas de la fachada de Notre-Dame-la-Grande de Poitiers en la que Jesé, representado únicamente de cintura para arriba - aunque por su postura puede deducirse que está de pie-, aparece igualmente como un personaje sin barba de cuya cabeza parte una especie de rama rematada en siete flores, símbolo de los dones del Espíritu ${ }^{16}$.
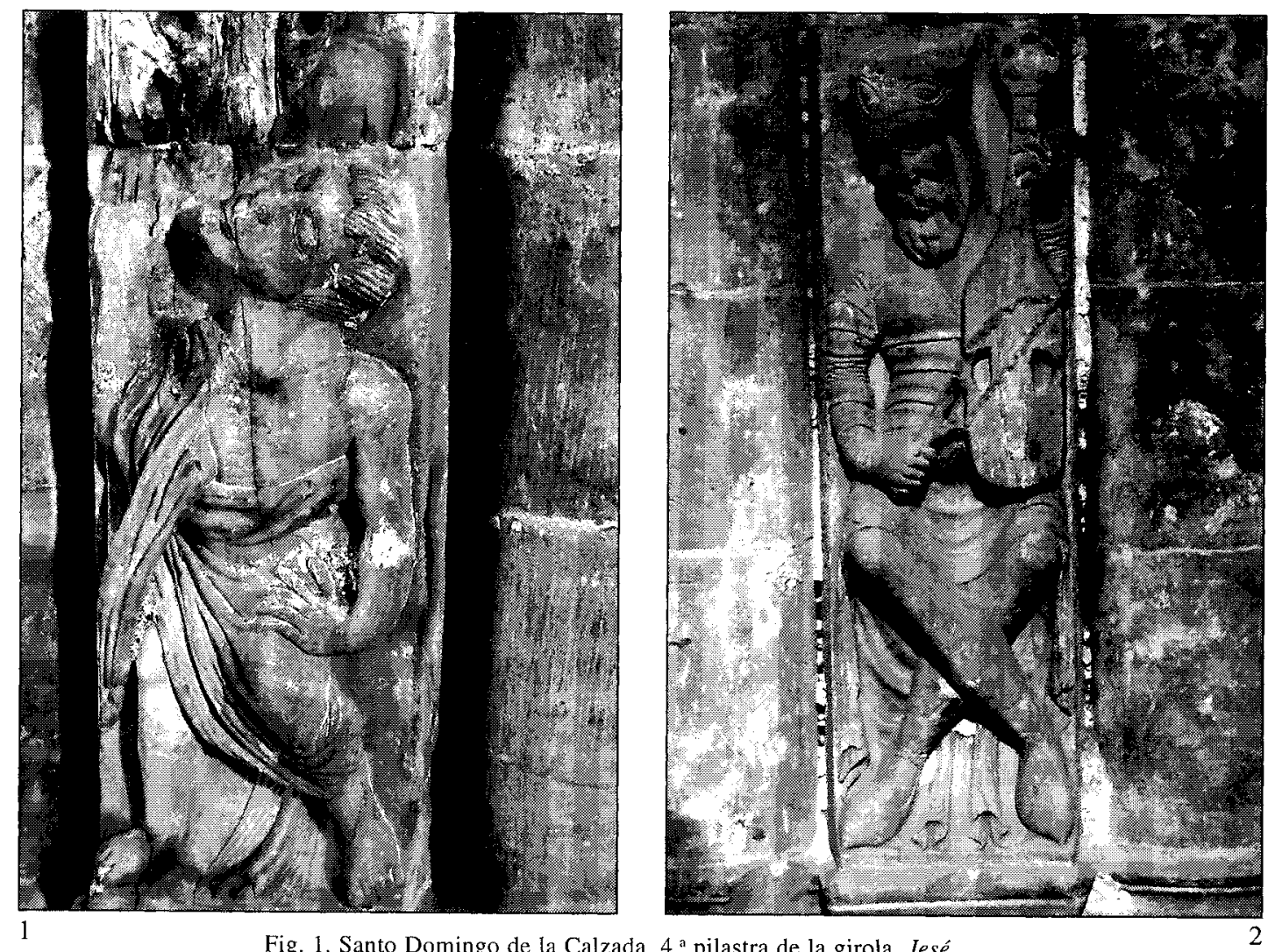

Fig. 1. Santo Domingo de la Calzada. $4 .{ }^{a}$ pilastra de la girola. Jesé

Fig. 2. Santo Domingo de la Calzada. 2." pilastra de la girola. Rey David.

${ }^{15}$ El Abbé Corblet se interroga sobre si esta postura no guardará analogía con el Sueño de Adán, durante el que Dios extrajo a Eva de su costado. Para él, si la Nueva Eva, reparadora de todas las faltas cometidas por la primera, ha de surgi de su estirpe, las circunstancias similares del sueño de ambos no hace sino presagiar este destino gozoso. Corblet, J., art. cit., pp. 54-55.

Para Watson, sin embargo, la analogía es mucho más precisa si se considera el Árbol de Jesé como el Árbol de la Cruz el Árbol de la Salvación - - [salutifera arbor]-, que según la leyenda, estaba asentado sobre el enterramiento de Adán. Watson, A., op. cit., p. 52.

${ }_{16}$ Aún se pueden citar otros ejemplos en los que Jesé no aparece tumbado, sino sentado como en el «Manuscrito Vysehrad» o en el «Evangeliario Krakovsky», o nuevamente de pie en la «Biblia de Saint-Bénigne de Dijon». Ibídem, p. 47. 
- En la base del otro soporte - [segunda pilastra]—, David, representante único de los Reyes de Judá en el conjunto riojano, fácilmente identificable al estar coronado, y por sostener en sus manos un instrumento músico de cuerda que parece tañer con la ayuda de un arco. (Fig. 2).

Su inclusión en el motivo genealógico busca destacar el origen regio del Mesías al hacerlo descender directamente de la familia real de Israel. De este modo quedan reunidas iconográficamente las tres naturalezas de Cristo: la divina al aparecer como hijo de Dios coronado por los dones del Espíritu; la humana, al haberse encarnado en María y así haber nacido de mujer; y la regia, al vincularse directamente como descendiente de la Monarquía bíblica.

Es precisamente la inserción de uno o más reyes lo que marca ciertamente la diferencia entre lo que ha quedado definido como fórmula verdadera y el resto de las representaciones del Árbol de Jesé, anteriores a la vidriera de Saint-Denis. Suger, en unos momentos en los que necesita por todos los medios prestigiar la monarquía capeta recurre a una metáfora visual que coloca estratégicamente en el lugar más representativo de la iglesia en la que se entierran los reyes galos desde época merovingia: desde la cabecera del templo, el Rey de Reyes imparte su bendición sobre sus representantes políticos en la tierra ${ }^{17}$. Así entendida, la representación de la genealogía de Cristo se convierte en una nueva imagen del poder, idea que tal vez, tampoco pueda resultarnos ajena en el caso riojano que nos ocupa si recordamos que el inicio de las obras de la catedral se sitúa en fechas muy cercanas a la conquista de la ciudad por Alfonso VIII quien, la recupera para la corona castellana después de que le hubiera sido usurpada - como tantos otros territorios suyos - por su tío el rey de León durante su minoría de edad, $\mathrm{y}$, quien, se vincula directamente a su construcción concediéndole numerosos donativos y privilegios ${ }^{18}$.

Respecto a los otros dos ejemplos hispanos, mientras que en el relieve silense no aparece ningún personaje coronado ni individualizado por cualquier otro tipo de atributos que pueda

17 «Le thème de la généalogie royale du Christ convenait done particulièrement au décor du chevet de l'église de SaintDenis. En même temps qu'il exaltait la royauté du Christ, préfigurée par celle de son ancêtre, "l'oint du Seigneur", il évoquait cette autre royauté capétienne, transmise elle aussi par hérédité et sacré par l'onction du saint chrêmè. Thérel, M.L., «Comment la patrologie peut éclairer l'archéologie. À propos de l'Arbre de Jessé et des statues-colonnes de Saint-Denis», Cahiers de Civilisation Médiévale, n. IV (1963), pp. 145-158, (p. 152). El tema también ha sido tratado por Crosby, S., The Royal Abbey of Saint Denis from its Beginnings to the Death of Suger. New Haven-London, 1987.

La misma intencionalidad de exaltación de la monarquía gala, esta vez a través del Árbol de Jesé de la catedral de Chartres y de su vinculación con ciertas ceremonias que en ella se celebraban para conmemorar la coronación de los reyes, ha sido puesta de relieve en el estudio que al particular dedicó por las mismas fechas Johnson, J. R., «The Tree of Jesse Window of Chartres: Laudes Regiae», Speculum, vol. XXXVI (1961), pp. 1-22: «The Tree of Jesse windows of Saint-Denis and Chartres are the visual counterparts in color and light of these hieratic ruler acclamations, at once a focal point of religious observance and many of many long-fostered political objectives of the Capetians»: (p. 6). Una lectura iconográfica de conjunto en la que se inserta la vidriera referida es la realizada por Katzellenenbogen, A., The Sculptural Programs of Chartres Cathedral. New York, 1964.

18 Sobre el presunto protagonismo del monarca castellano en la colocación de la primera piedra del templo es de particular interés el testimonio del cronista principal de la ciudad quien nos narra: «En el año yà referido de mil ciento y sesenta y ocho, los Castellanos cansados del govierno de el Rey de Leon Don Fernando, y viendo yà de onze años, ò mas, a D. Alfonso su legitimo Rey, hijo de Don Sancho el Deseado, le juraron, pareciendoles de edad bastante, para governar el Reyno, que heredava, como lo experimentaron en su gran talento, haziendole luego dueño de todas las Ciudades y tierras, que le pertenecian, (...). Ganò las provincias de Rioja, y Bureva, y en esta ocasion visitò el Sepulcro de nuestro Santo, y el Obispo Don Rodrigo la tuvo, de consultarle su deseo de ampliar aquella Iglesia, y pedirle su Real ayuda, que el nobilissimo Rey ofreciò magnanimo, y ambos Rey, y Obispo, para empezar la fábrica, pusieron la primera piedra, (...)». González Tejada, J., Historia de Santo Domingo de la Calzada, Abrahan de la Rioja, Patrón del Obispado de Calahorra, y La Calzada y noticia de su fundación, y aumentos de la Santa Iglesia Cathedral, y ciudad nobilissima de su nombre, sus hijas. Compuesta por.. Madrid, 1702, pág. 191. (Se ha manejado la edición facsímil publicada en Logroño, 1985, aunque respetándose la paginación original del texto del siglo $\mathrm{x} v \mathrm{HII}$ ).

Documentos firmados por Alfonso VIII en los que se citan las obras quedan recogidos en las recopilaciones de González, J., El Reino de Castilla en la época de Alfonso VIII. 3 vols. Madrid, 1960; López de Silanes, C. y Sáinz Ripa, E., Colección Diplomática Calceatense. Archivo Catedral (1125-1450). 2 vols. Logroño, 1985-1991; y en los Cartularios (I, II y III) de Santo Domingo de la Calzada. (Ed. e índices por Agustín Ubieto Arteta). Zaragoza, 1978. 
indicarnos que estamos ante alguno de los reyes de los hebreos ${ }^{19}$, en el parteluz de la catedral de Santiago son dos los representados, David, igualmente como músico que en este caso lo que está tocando es el arpa tradicional de su iconografía, y Salomón, sentado con las piernas cruzadas de forma que recuerda el gesto de administración de justicia ${ }^{20}$. Y nuevamente en este caso, atendiendo a la opinión de S. Moralejo, «es posible que la imaginería regia del Pórtico, indudablemente bíblica, se ofreciera también como referente simbólico o arquetipo ideal de la dinastía reinante, en los términos alusivos o asociativos que se han propuesto para las series de los reyes de Judá en portadas del dominio real francés o en las ubicuas representaciones del Árbol de Jesé»» ${ }^{21}$.

- Siguiendo el ascenso por el soporte en el que se ha representado el motivo principal, y que parte de la representación ya analizada de Jesé, encontramos la figura de la Virgen. Aunque se ha perdido el rostro como consecuencia de las obras de acoplamiento del retablo, no podemos dudar que nos encontramos ante una figura femenina sentada, en posición frontal, hierática pero majestuosa. Es en ella en quien se cumplen en primera instancia las profecías hechas por Isaías al pueblo de Israel; es la rama que ha brotado de la raíz de Jesé, y por lo tanto ocupa un lugar destacado en el Árbol ${ }^{22}$. Como se ha indicado más arriba, no es la Theotokos frecuente en los ejemplos europeos sino que los gestos que realiza con sus manos, recogiéndose la túnica con la izquierda mientras que dirige la derecha hacia el pecho con la palma abierta hacia el espectador en actitud de sorpresa, nos llevan a relacionarla con la Virgen de la Anunciación, con el momento mismo en el que el Hijo de Dios se encarna milagrosamente en María adquiriendo así su naturaleza humana a la par que el ángel recuerda simultáneamente su estirpe regia al anunciar que «el Señor Dios le dará el trono de David, su padre» ${ }^{23}$ (Fig. 3).

Dos son los datos con los que podemos contar para apoyar esta identificación. El primero de ellos es el que aporta uno de los capiteles del anillo exterior de la girola de la propia catedral calceatense en el que se ha representado el tema de la Anunciación-Coronación, y donde la Virgen, esta vez de perfil y en presencia del ángel, reproduce exactamente los mismos gestos que la pieza que nos ocupa. El segundo, una de las figuras de la otra pilastra cuyas características nos llevan a pensar en una representación del arcángel Gabriel. Colocada prácticamente a la misma altura que la imagen de María, ésta a la que se ha colocado recientemente la cabeza, está vestida con una amplia túnica de plegado similar a la de la Madre de Dios detrás de la que asoman dos alas de detalladas plumas. Los brazos están mutilados por lo que no

\footnotetext{
${ }_{19} \mathrm{Al}$ referirse al mismo, en comparación con el gallego, E. Valdez dice de él que, «Como genealogía es más breve, ascendiendo directamente desde Jesé a María y después a la Trinidad, enfatizando, de esta forma, las dos naturalezas de Cristo». Valdez del Álamo, E., art. cit., (1991), p. 199.

El único investigador que cita entre los personajes de la escena de Silos a dos reyes, que identifica con David y Salomón, es S. Moralejo, quien piensa que son dos de las seis figuras que se disponen a ambos lados del tronco central y de los que dice que «se los margina al lugar que ocupan los profetas». Moralejo, S., «El 1 de abril de 1188. Marco histórico y contexto litúrgico en la obra del Pórtico de la Gloria», El Pórtico de la Gloria. Música, Arte y Pensamiento. Santiago de Compostela, 1988, pp. 19-37, (pág. 28).

20 Yarza Luaces, J., El Pórtico de la Gloria. Madrid, 1984, pág. 34. Que el personaje adopte esta postura hacen indicar al Prof. Yarza que tal vez estemos ante una alusión al famoso juicio.

${ }^{21}$ Moralejo, S., art. cit., p. 27.

${ }^{22}$ Hasta estos momentos, la figuración del Árbol de Jesé era la representación plástica de la genealogía de Cristo, como ya se ha dicho a lo largo de este estudio; pero desde fines del siglo xil, y debido sobre todo a los escritos del Cister, la figura de María va cobrando progresivamente un valor y un protagonismo que en ningún modo había disfrutado antes durante los siglos del Románico, hasta llegar a apropiarse para sí motivos en los que antes no era sino un personaje más y que ahora se vinculan directamente a su persona como es el caso. Como escribió Mâle: «La Vierge - [en los ejemplos de mediados del siglo XII] - se tient à son rang, sous les pieds de son Fils. Plus tard, quand le culte de la Vierge grandira, c'est elle qui sera la suprème fleur de l'arbre; (...). L'arbre de Jessé devient alors l'arbre généalogique de la Vierge». Mâle, É., op. cit., p. 174.
}

${ }^{23}$ Lc. 1,32 . 

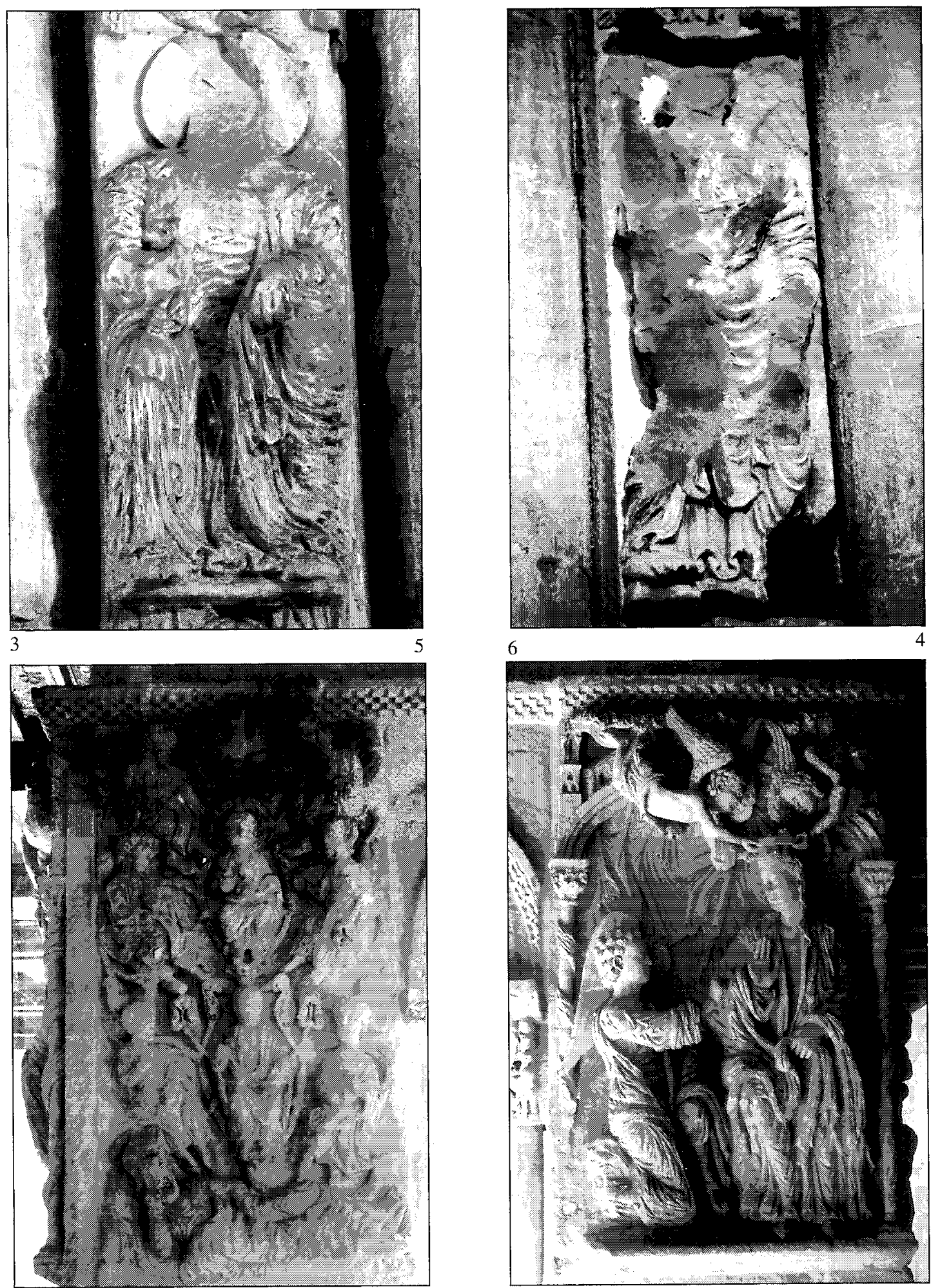

Fig. 3. Santo Domingo de la Calzada. 4. ${ }^{a}$ pilastra de la girola. Virgen.

Fig. 4. Santo Domingo de la Calzada. 2." pilastra de la girola. Arcángel Gabriel.

Fig. 5. Santo Domingo de Silos. Claustro. Árbol de Jesé.

Fig. 6. Santo Domingo de Silos. Claustro. Anunciación-Coronación. 
podemos adivinar cuáles serían sus movimientos, pero tanto el cuerpo como el rostro están girados y sus pies parecen dirigirse hacia el personaje que tiene justo enfrente, como hemos indicado, la Virgen. (Fig. 4).

La vinculación de este episodio bíblico a la imagen del Árbol de Jesé, aunque ajena a la plástica europea del momento, no resultaba extraña sin embargo al mundo de las ideas sobre todo tras los sermones de San Bernardo quien, como apunta G. Schiller, relacionó los textos de Isaías $11,1^{24}$ y $7,14{ }^{25}$ con la Anunciación y la Concepción Virginal respectivamente ${ }^{26}$. El santo abad de Clairvaux muestra especial interés en su explicación de la profecía por demostrar la pureza de María, para lo que encuentra también el equivalente en el origen mismo de la vara, «porque ésta floreció sin semilla y la Virgen concibió sin varón. Y si cuando germinó la flor no se quebró la vara, tampoco el parto sagrado lesionó la pureza de la Virgen» ${ }^{27}$. Y una vez cumplido este objetivo primordial, procede a clarificar cuál es el verdadero «reino» que hereda Cristo de David su ancestro: «Es evidente que la ascendencia del Señor Jesús entronca con el linaje de David. (...). En realidad, Dios le entregó el trono de David, su padre, cuando le ungió rey sobre Sión, su monte santo. (...). El Señor Dios, por tanto, le dará el trono de David, su padre, no el trono simbólico, sino el real; no el temporal, sino el eterno; no el terreno sino el celestial» ${ }^{28}$. Entre otros escritos suyos, hay que destacar estos sermones como el origen del progresivo protagonismo que irá cobrando la Virgen en la iconografía del Árbol ${ }^{29}$.

Esta asociación Anunciación-Árbol de Jesé no es única al ejemplo calceatense. En Santo Domingo de Silos si bien no forman parte de la misma escena no pueden estar asociadas de modo más estrecho ya que se muestran en dos imágenes sucesivas, tema cada una de ellas de los dos relieves contiguos que decoran el machón suroccidental del claustro dando frente a una de las puertas que comunicaban este recinto con las estructuras de la parte oeste del monasterio románico, de modo que cuando los monjes la traspasaban se encontraban de golpe con la visión de la profecía y su cumplimiento. Esto cobraba un especial significado durante el oficio de maitines de la fiesta de la Encarnación, que según la liturgia medieval practicada en Silos, se componía de una lírica combinación de lecturas del profeta Isaías y de responsorios que describían la misma Anunciación ${ }^{30}$. (Figs. 5 y 6).

El caso compostelano es más complejo. Aquí, rematando el fuste del parteluz, la Virgen, sentada de perfil y coronada como en el relieve burgalés, no está acompañada por el ángel sino flanqueada por dos delicadas figuras que han sido identificadas como sibilas ${ }^{31}$ o que incluso se ha apuntado la posibilidad de que fueran las parteras que, según los Apócrifos, asistieron a María durante el parto testificando su virginidad maternal milagrosa ${ }^{32}$. Pero, de cualquier

24 «Saldrá un vástago del tronco de Jesé, y un retoño de sus raíces brotará».

25 «Pues bien, el Señor mismo va a daros una señal: He aquí que una doncella está en cinta y va a dar a luz un hijo y le pondrá por nombre Emmanuel».

${ }^{26}$ Schiller, G., Iconography of Christian Art. London, 1971, vol. I, pág. 15. A este respecto indica cómo: «He draws a parallel between the words "the spirit of the Lord shall rest upon him" and the Holy Ghost overshadowing Mary, which was interpreted as meaning that she conceived supernaturally at the Annunciation». Ibidem.

27 «In hoc tamen Isaiae testimonio, florem Filium, virgam intellige Matrem, quoniam et virga floruit absque germine, et virgo concepit non ex homine. Nec virgae virorem floris laesit emissio, nec virginis pudorem sacri partus editio». San Bernardo, op. cit., Homilía II, 6. (Cf., en Obras Completas, vol. II, pp. 620-621).

${ }^{28}$ «Quod de estirpe David originem duxerit Dominus Iesus, nemo dubitat. (...). Tunc sane dedit illi Deus sedem David patris sui, quando constitutus est rex ab eo super Sion montem sanctum eius. (...). Dabit, ergo, ie Dominus Deus sedem David Patris sui, non typicam, sed veram, non temporalem sed aeternam, non terrenam sed caelestem». Ibidem, Homilía IV, 1. (Cf., Ibidem, pp. 658-659).

${ }^{29}$ Sobre el papel que pudieron jugar los diferentes escritos de San Bernardo en la codificación del tema, vid.: Hufgard, M. K., «St. Bernard of Clairvaux and the Early Gothic Tree of Jesse Theme», Cistercian Studies, vol. XXII (1987/4), pp. 316-322.

${ }^{30}$ Valdez del Álamo, E., art. cit. (1990), p. 173.

31 Ibídem, pág. 181, y, Valdez del Álamo, E., art. cit., (1991), p. 199.

32 Yarza Luaces, J., op. cit., p. 34 
modo, su postura es reveladora girando la cabeza hacia la derecha, mientras se recoge el manto con una mano y nos muestra la palma de la otra abierta a la altura del pecho en la primera y casi única alusión a la Virgen en una obra tan compleja y cargada de imágenes como el Pórtico ${ }^{33}$. Para E. Valdez, «lo más significativo es que los conceptos y los elementos formales de la Anunciación de Silos parece que han sido incorporados en el parteluz: la Virgen Reina, Madre de Dios, que acepta su papel en la salvación de la humanidad, ocupa su lugar propio en la genealogía de Cristo» ${ }^{34}$ (Figs. 7 y 8 ).

- Si hemos considerado la representación anterior como una particularidad iconográfica no presente sino en los tres ejemplos hispanos, otro tanto habremos de hacer con el motivo que remata la serie: la Trinidad «Paternitas». Las vidrieras de Saint-Denis y Chartres culminan con una representación de Cristo en majestad, entronizado y rodeado por siete palomas, reflejo de los siete dones del Espíritu de los que habla el profeta ${ }^{35}$. Sin embargo, en Santo Domingo de la Calzada, la cúspide está ocupada por Dios Padre quien, sentado en su trono con corona y nimbo crucífero, sostiene sobre sus rodillas al Niño Dios bendiciendo. La placa sobre la que están tallados está rota en su parte superior, pero todavía queda el resto de lo que fue un ave, representación única del Espíritu Santo ${ }^{36}$. Prueba posible de que pese a su estado actual estas figuras conformaban un grupo trinitario son alguno de los documentos medievales en los que se menciona explícitamente la Trinidad como la advocación de la capilla mayor ${ }^{37}$. (Fig. 9).

Y una vez más, los árboles de Jesé silense y compostelano terminan igualmente con una representación de Dios, Uno y Trino, según el tipo Paternitas ${ }^{38}$. En el claustro burgalés, para enfatizar el concepto de generación eterna, el artista ha esculpido al Hijo desnudo, como representación conventual de un alma ${ }^{39}$, emergiendo del seno del Padre, coronado y con nimbo crucífero adornado con un motivo avenerado. Sobre ellos, y rodeada por un elemento vegetal, desciende la paloma. En el Pórtico de la Gloria, la Trinidad ocupa el capitel del parteluz y está flanqueada por cuatro ángeles turiferarios, dos a los lados de la Majestad, esculpida en el espacio de la cesta, y dos a los lados de la paloma, tallada en el cimacio. En este caso, Dios Padre abraza cariñosamente a su Hijo quien extiende los brazos sujetando en una de sus manos el Libro de la Revelación.

Que lo que se ha querido representar en la catedral riojana es a la Santísima Trinidad y que su vinculación al tema del Árbol de Jesé no se ha debido pues a algo accidental o a un error en la copia del posible modelo, es algo que se puede demostrar si atendemos a la fuente de inspiración del iconograma: la consideración de Cristo como «Logos», uno e indivisible con

\footnotetext{
33 Ibidem.

34 Valdez del Álamo, E., art. cit. (1991), p. 200.

35 «Reposará sobre él el espíritu de Yahveh: espíritu de sabiduría e inteligencia, espíritu de consejo y fortaleza, espíritu de ciencia y temor de Yahveh». (Is. 11,2).

36 Sobre las diferentes características de este particular tipo iconográfico es interesante consultar la obra de Pamplona, G. de, Iconografía de la Santísima Trinidad en el arte medieval español. Madrid, 1970, pp. 65 y ss.

371442 agosto 25. Santo Domingo de la Calzada. El cabildo catedral de La Calzada manda hacer un traslado autorizado de los estatutos de la cofradía fundada por Santo Domingo y de la memoria pormenorizada de las indulgencias que los santos padres, arzobispos y obispos concedieron a los fieles que asisten a los cultos de la iglesia catedral o ayudan con sus limosnas a las obras que en ella se realizan. En uno de los párrafos se menciona: «...Iten todos los que venieren el dia de la Trenidat a la dicha iglesia de santo Domingo que es la bocaçion en el altar mayor de la dicha iglesia son otorgados doze años e nuebe dias de perdon a cada una de las dichas oras». ACSD. Leg. 2/14. (Publicado por López de Silanes, C. y Sáinz Ripa, E., op. cit., pp. 182-183).

${ }^{38}$ Otros dos ejemplos de este motivo iconográfico que como se puede ver gozó de gran predicamento dentro de la escultura tardorrománica hispana son los que aparecen en los tímpanos de Santo Tomé de Soria y de San Nicolás de Tudela. Según E. Valdez, y en función del marco y de la escena en la que se han inscrito cada uno de ellos, «los tímpanos de Soria y Tudela se centran en la divinidad de Cristo. En cambio, los ejemplares de Silos y de Santiago expresan su doble naturaleza». Valdez del Álamo, E., art. cit. (1990), pág. 183.

${ }^{39}$ Ibidem, p. 180.
} 

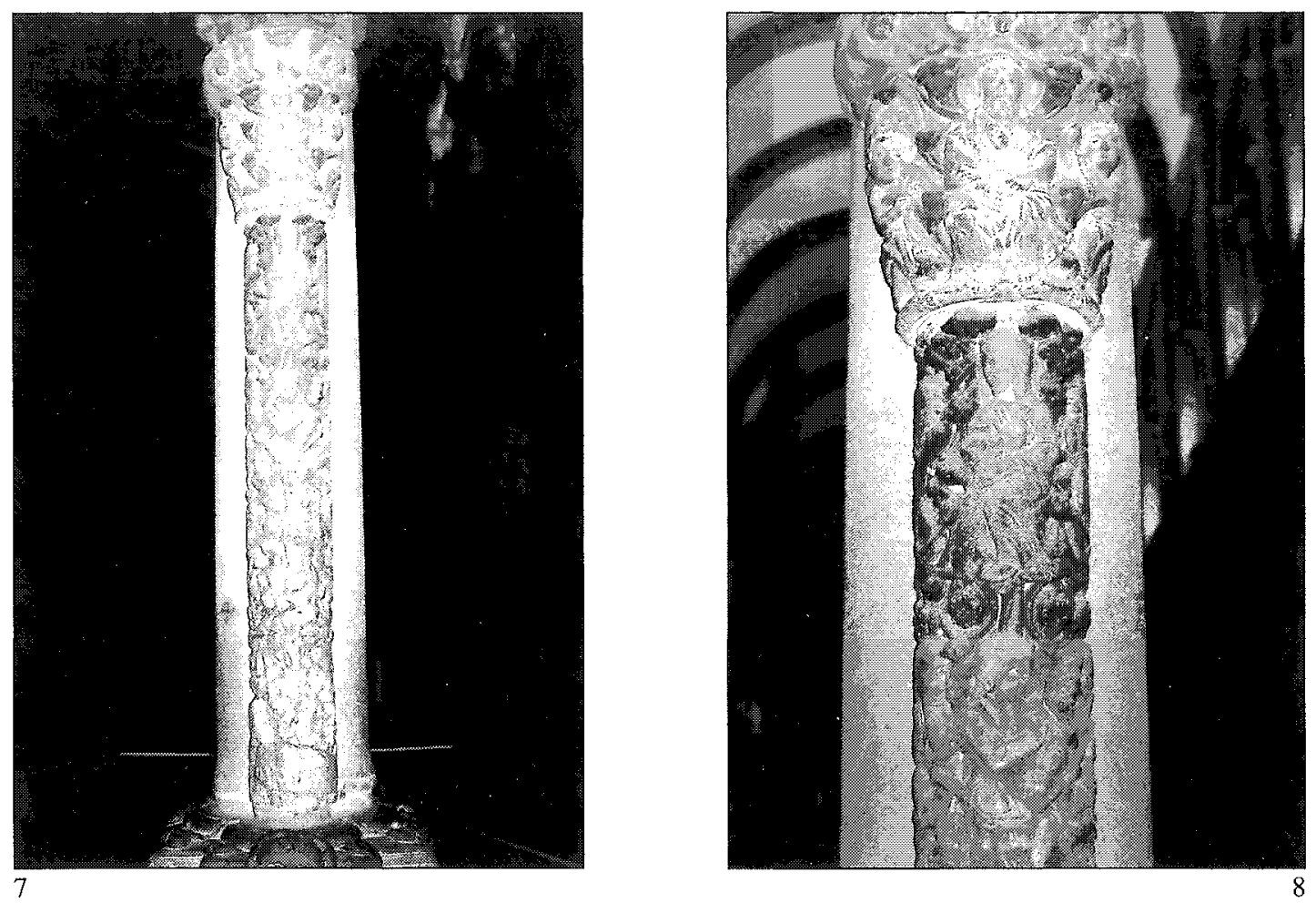

9

10
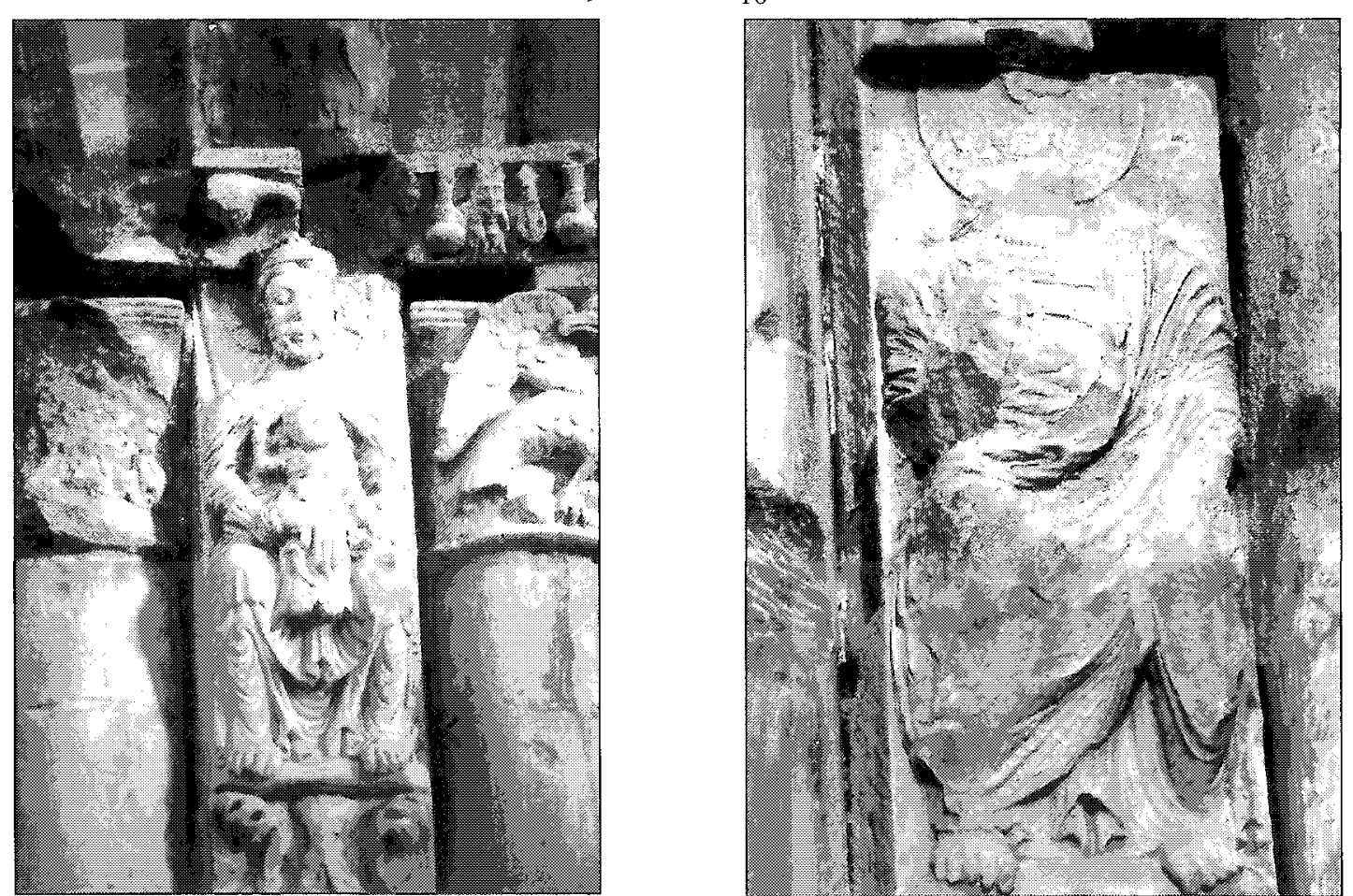

Fig. 7. Santiago de Compostela. Pórtico de la Gloria. Parteluz.

Fig. 8. Santiago de Compostela. Pórtico de la Gloria. Parteluz (detalle)

Fig. 9. Santo Domingo de la Calzada. 4. " pilastra de la girola. Trinidad.

Fig. 10. Santo Domingo de la Calzada. 2." pilastra de la girola. Isaías. 
el Padre, de quien procede, según narra el evangelio de San Juan en su comienzo ${ }^{40}$, y que en opinión de G. Schiller, esta consubstancialidad del Hijo con el Padre fue desde los orígenes considerada mucho más como un problema trinitario que como una cuestión cristológica ${ }^{41}$. Pues son precisamente estas dos primeras palabras del inicio del citado evangelio, «in principio», las que se tallaron sobre un rótulo que sujeta con las garras el águila que se sitúa inmediatamente a la izquierda del relieve de la Trinidad, y que es la figura que remata el esquinazo que hace frente a la capilla mayor del amplio capitel que decora en su cara lateral, con un friso de vírgenes necias y prudentes, este soporte exento de la girola ${ }^{42}$. El remate del capitel simétrico está completamente destruido, pero podemos aventurar que en él se hubiese representado de nuevo el águila de San Juan, ya que el único resto que podemos identificar del mismo es el ala de un ave.

No deja de resultar curioso que dentro del mismo sermón de San Bernardo antes aludido para explicar una de las novedades iconográficas del conjunto riojano, se dedique un amplio espacio a este tema de la indivisibilidad Padre-Hijo ${ }^{43}$.

Es E. Valdez quien seguramente nos de la clave del auge de este tipo de representaciones sobre suelo hispano al buscarla en las especiales circunstancias de la España de la Reconquista donde «creer en la Trinidad es el artículo fundamental de fe que separa a los cristianos de los judios y de los musulmanes» ${ }^{44} ; \mathrm{y}$, remontándonos aún más en el tiempo, si advertimos que las relaciones entre Encarnación y Trinidad son una constante en la iglesia hispana desde que llamara la atención sobre ello el IV Concilio Toledano (638), en un intento más por combatir la doctrina arriana que suponía el principal peligro para la ortodoxia en los tiempos de la monarquía católica hispanogoda ${ }^{45}$.

- Un grupo más o menos amplio de Profetas, según el caso, suele completar la representación del Árbol de Jesé. Éstos, ancestros de Cristo según el Espíritu ${ }^{46}$, suelen situarse a ambos lados del vástago central portando en sus manos las banderolas sobre las que se inscriben las profecías por ellos reveladas que anunciaban la venida del Salvador; en ocasiones pueden ir acompañados también de sibilas - [como sucede en Compostela] - u otros personajes paganos como Virgilio quienes desde su posición también se hicieron eco de estos sucesos. Igualmente, no es rara la presencia dentro de este grupo de los Patriarcas del Pueblo de Israel como ascendientes primeros de Cristo según la carne y con quienes estableció Yahvé directamente su alianza. Sin embargo, no siempre aparecen figurados sin que por ello se desvirtúe el sentido de la composición ${ }^{47}$. Presentes en Silos y Santiago según los cánones tradicionales a ambos lados del tronco principal, en Santo Domingo de la Calzada la representación es doble. Por una parte, las recientes labores de restauración de las piezas han sacado a la luz una inscripción en el nimbo de uno de los personajes de la segunda pilastra: el dispuesto tras los motivos vegetales

\footnotetext{
40 «En el principio existía la Palabra y la Palabra estaba con Dios, y la Palabra era Dios».- (Jn. 1, 1).

${ }^{41}$ Schiller, G., op. cit, vol. 1, p. 5.

${ }^{42}$ La transcripción latina del rótulo es la recogida por Moya Valgañón, J. G., Etapas de construcción de la catedral de Santo Domingo de la Calzada. Logroño, 1991, p. 34. Por su parte, Íñiguez y Álvarez-Coca lo citan castellanizado: «en principio». Íñiguez Almech, F., «Sobre tallas románicas del siglo xi», Príncipe de Viana, n. ${ }^{\circ} 112-113$ (1968), pp. 181-235 (p. 222); y Álvarez-Coca, M." J., La escultura románica en piedra en la Rioja Alta. Logroño, 1978, p. 51.

43 «Y de la misma manera: el que fue engendrado del Padre antes de todos los siglos, en adelante será tenido por hijo tuyo. En consecuencia, será hijo tuyo lo que nació del Padre, y lo que nacerá de ti será Hijo suyo, sin ser dos hijos, sino uno». San Bernardo, op. cit., Homilía IV, 4. (Cf. en Obras Completas, vol. II, pp. 664-667).

44 Valdez del Álamo, E., art. cit. (1990), p. 180.

45 Orlandis, J. y Ramos-Lisson, D., Historia de los Concilios de la España romana y visigoda. Pamplona, 1986, p. 312.

${ }^{46}$ Corblet, J., art. cit., p. 113.

47 «The Tree of Jesse is a theme with variations, and a Prophet-group is only one kind of accompaniment. It is not an essential feature». Watson, A., op. cit., p. 9.
} 
que siguen al Rey David, y justo bajo la figura que hemos identificado como el arcángel Gabriel. Esta escultura sedente, frontal e hierática queda identificada por la citada inscripción precisamente como Isaías, responsable de la profecía origen del iconograma. (Fig. 10). Por otra parte, en un espacio tan cercano a los soportes de la girola en los que se ha tallado el motivo principal, comunicado además visualmente con el presbiterio, como es la capilla central del ábside — capilla de San Pedro_, aparecen talladas como remate de los parteluces que dividen cada una de las tres ventanas unas figuritas de pequeño tamaño, unos quince centímetros cada una, sedentes, barbadas, luciendo collares de perlas y en actitudes tranquilas, que llevan en sus manos unas cartelas sobre las que se escribieron sus nombres pudiéndose leer Isaac en el de la izquierda, en el central Abraham, y Jacob en el de la derecha ${ }^{48}$. Es Íñiguez el primero que nos habla de ellas y ya entonces se plantea la cuestión de si representan o no a los ascendientes de Jesús, explicación que para él es creíble sin esfuerzo ${ }^{49}$, y que nosotros consideramos como una hipótesis bastante posible.

No queremos cerrar este apartado sin antes observar que la aparente falta de unidad y de coordinación que presenta el conjunto, con figuras repartidas entre dos pilastras y con otras intercaladas sin significación aparente, junto a placas que han tenido que ser recortadas para encastrarse en la secuencia, no creemos que se deba a un caótico plan inicial, sino que tal vez debamos considerarlo consecuencia de una colocación posterior a su ejecución por artífices distintos a aquellos que las labraron, y desconocedores por lo tanto de su correcto significado ${ }^{50}$.

\section{Fuentes posibles de la imagen}

Los caracteres iconográficos específicos del Árbol de Jesé riojano que acabamos de reseñar - considerando, además, que no se tiene noticia de representación alguna de la genealogía de Cristo en el arte español hasta llegar a estos conjuntos tardorrománicos-, nos conducen a pensar en la existencia de algún texto concreto, vinculado de algún modo a la catedral calceatense, que explicase las diferencias entre éste y el resto de los ejemplos ultrapirenaicos anteriores en el tiempo y por lo tanto, precedentes plásticos a tener en cuenta.

Tal vez la respuesta se encuentre en el propio Archivo Catedral. Entre todos los documentos que lo integran se conservan cinco códices que fueron dados a conocer a mediados del presente siglo por el Padre Leclercq ${ }^{\text {st }}$. Este autor, al hablar del Códice $3 .^{\circ}$, que fecha en los ss. XII-XIV, hace mención expresa de los cinco últimos folios, escritos con caligrafía del siglo XIV y que se componen de sermones, comenzando el primero del siguiente modo: «Gloriosissimam dei genitricem Mariam beatus Bernardus per decorem Carmeli commendans» ${ }^{52}$. Tal vez nos encontramos ante el mismo sermón de San Bernardo al que nos hemos venido refiriendo de modo reiterado en el texto ya que en él quedaban expuestas las características particulares que revestía el grupo escultórico. Si esto es así, ¿por qué no pensar que ésta no es sino una copia del xIv de un original presente en la catedral dos siglos antes y que tal vez a causa de su dete-

48 Moya Vaigañón, J. G., op. cit., pp. 32-33

49 Íñiguez Almech, F., art. cit., p. 214.

so La permanencia de los relieves en la lonja hasta su posterior colocación en el lugar para el que fueron concebidos, una vez finalizadas las labores arquitectónicas de esta parte del templo, fue idea apuntada por el Prof. Bango en el congreso dedicado a la cabecera de esta catedral mencionado al inicio de este trabajo: Bango Torviso, I. G., «La cabecera de la catedral calceatense y la arquitectura hispana de su época», La cabecera de la Catedral calceatense y el Tardorrománico hispano. Actas del Simposio en Santo Domingo de la Calzada, 29 al 32 de enero de 1998. Santo Domingo de la Calzada, 2000 , pp. $11-150$

${ }^{51}$ Leclercq, J., «Textes et Manuscrits de quelques biblioteques d'Espagne», Hispania Sacra, (1949/1), pp. 91-118.

52 Ibidem, p. 104. 
rioro se desea preservar mediante una réplica? Es algo que no podemos afirmar categóricamente ya que no disponemos de más pruebas, pero que dadas las evidentes coincidencias, consideramos interesante tener en cuenta.

También en el mismo Archivo y dentro del Códice $2 .^{\circ}$, datado por Leclercq en el siglo XIII, pero adelantada recientemente su cronología a la duodécima centuria ${ }^{53}$, queda recogido un tratado sobre el segundo de los aspectos que ha centrado de manera más amplia nuestra atención: la Trinidad. El folio 80 queda encabezado del siguiente modo: «Incipiunt capitula primi libri sententiarum de Misterio Trinitatis» ${ }^{54}$ confirmando de este modo el interés especial mostrado por el cabildo calceatense por la cuestión trinitaria desde sus orígenes que les llevó incluso a hacer de ésta la advocación del altar principal del templo.

Expuestas así las cosas, no quedaría sino tratar de averiguar cuál de los tres conjuntos escultóricos a los que nos hemos venido refiriendo a lo largo del texto fue creado en primer lugar y pueda ser considerado así el modelo de los otros dos. Dada la evidente vinculación técnica y la comunidad de estilo apreciable entre ellos, productos todos de los años finales del siglo xII, deberá ser un profundo análisis estilístico comparativo, y no es éste el lugar para ello, el que determine a quien corresponde la primacía y, con ello, la creatividad iconográfica que ha sido el objeto de este estudio.

Marta Poza Yagüe

Lda. Universidad Autónoma de Madrid

\section{MISCELÁNEA SOBRE ESCULTURA GENOVESA EN ESPAÑA ${ }^{1}$}

El estudio de obras italianas que de manera ininterrumpida fue llegando a España se viene haciendo desde hace ya muchos años. Pero se han estudiado preferentemente los grandes conjuntos sepulcrales o retablísticos tallados en mármol ${ }^{2}$ y se ha prestado menor atención a la escultura religiosa devocional que también llegó en gran cantidad y que ejercerá su influencia entre los artistas de la manera tradicional ${ }^{3}$. En este aspecto las zonas italianas para nosotros más interesantes han sido Génova y Nàpoles desde donde, por los más diversos conductos, nos llegó un elevado número de piezas.

Como una breve aportación más al catálogo genovés pretendemos con estas líneas dar a conocer unas piezas que no tienen, tal vez, más en común que el conservarse en distintos lugares de la Comunidad castellano-manchega. De todas, posiblemente, la de más interés y, por otra parte, la única que está plenamente documentada es el delicioso boceto de la Virgen con el

${ }^{33}$ López de Silanes, C. y Sáinz Ripa, E., op. cit., vol. I, p. 261.

${ }^{54}$ Ibidem.

1 Este trabajo forma parte de un proyecto de investigación financiado por la DGES (PB 98-0708).

Deseamos agradecer al Ilmo. Sr. D. Santos Saiz-Gómez, deán del Ilmo. Cabildo Catedral de Cuenca, la amable colaboración prestada para el estudio de algunas de estas obras.

${ }^{2}$ La bibliografía sobre el tema es ya muy numerosa. Solamente queremos destacar la tan conocida del Marqués de Lozoya: Escultura de Carrara en España, C.S.I.C., Madrid, 1957 y López Torrijos, Rosa: «La Scultura Genovese in Spagna», en La Scultura a Genova e in Liguria. Dalle Origini al Cinquecento, Vol. I, Génova, 1987.

${ }^{3}$ Como un gran esfuerzo en este sentido debe ser destacada la obra de Aranda Linares, Carmen. Hormigos Sánchez, Enrique y Sánchez Peña, José Miguel: Scultura Lignea Genovese a Cadice nel Settecento. Opere e Documenti, Génova, 1993. 